\title{
Pathology of Accounting Systems and Financial Reporting of Small Business
}

\author{
Fateme Soghra Yaghubi (Corresponding author) \\ College of the Accounting and Management \\ University of Sistan and Bluchestan, Zahedan, Iran \\ E-mail: yaghoobifateme@yahoo.com \\ Mohammad Ali Moradi \\ College of the Accounting and Management \\ University of Sistan and Bluchestan, Zahedan, Iran \\ E-mail: m_ali_moradi@yahoo.com \\ Mehrdad Mazaheri \\ College of the Education and Psychology \\ University of Sistan and Bluchestan, Zahedan, Iran \\ E-mail: mazaherimehrdad@gmail.com
}

$\begin{array}{lr}\text { Received: July 28, } 2011 & \text { Accepted: September 9, } 2011 \quad \text { Published: November 21, } 2011 \\ \text { doi:10.5430/ijba.v2n4p75 } & \text { URL: http://dx.doi.org/10.5430/ijba.v2n4p75 }\end{array}$

\begin{abstract}
Achieving the management in every economic unit needs having reliable and in time information. Proving to be true requires establishing a suitable accounting system for collecting, processing and reporting the effects and results of activities and exchanging them around the environment of the economic establishment activation.

The initial consideration indicates that a great part of some small economic establishments Haven't hat suitable accounting systems to providing timely and reliable information for achieving the responsibility of responding and helping the management decision making process. Base on these the first and main gold of current study is to pathology the accounting systems and financial reporting in small companies. Statistical sample of these studies has been chosen among small but active companies in economical environment in sistan and bluchestan and during the financial periods from 2007 to 2009.

The study findings shows that some factors like employees experience in financial parts, the space between business needs of the accounting employees and collegiate training in relevant fields, suitable systems of compensation for the employees service in financial parts and the management awareness of financial subject in business units , is directly relation with the efficiency of accounting systems and financial reporting . and some factors like scientific competency and legal and contractual necessities in attracting the employees in financial units and taxation controls on the company's financial activation doesn't have any significant relation whit efficient of accounting systems and financial reporting.
\end{abstract}

Keywords: Pathology, Financial Accounting and Reporting Systems, Small Businesses

\section{Introduction}

Nowadays we cannot manage even the very small business units without the right information at the right time. This information is used by the managers and executives inside an organization, and by investors, creditors, and other people having rights, benefits and interests in the business unit outside an organization. Providing the essential information to manage a business unit requires establishing a proper information system. The small business units are often undervalued, but it is worth mentioning that even in the U.S., the most important home for multi-national companies, 
small units with less than 100 employees account for more than $40 \%$ of the economical employment, and $95 \%$ of the active business units hold less than 20 people. We can clearly regard the small business units as a major factor (Jamaranian 1381). Likewise, in our country, small units account for a major part of the economical units. These units, like the other business units, need reliable accounting information to evaluate the financial status and the function result, and to make managing decisions. Having this information requires possessing a desirable accounting system so that it can fulfill the informational needs of the users.

However, unfortunately the kind of information normally available for the small units do not fulfill their needs and one of the main reasons for the small business units to fail and not to succeed is lack of sufficient and reliable accounting information. So this article looks at the accounting system and financial reporting from a pathological point of view, and investigates the reasons and the factors effective on inefficiency and weakness of accounting systems and financial reporting in these units.

\section{The Statement of the Problem and the Main Question of the Research}

It is obvious that the managers of the organizations encounter the situations that require making right decisions. Therefore, we can assume that the fundamental output of a manager is to make right decisions at the right time, and what can help him/her achieve this is having access to (understandable, related, reliable and comparable) information and making proper use of it in decision-makings (Talebi, 2002). Additionally, in most of the organizations, the majority of the decisions made by the managers are related in different ways to the financial information, so the financial information often plays a key role (Esmaeili, 1999). Undoubtedly, providing the necessary information to manage every business unit requires establishing a desirable and proper accounting system (Amiri, 2000).

Therefore, scientific management and knowledge-oriented organizations are always in need of designing and implementing systems in order to provide the necessary information for the managers for making right decisions in optimum allocation of resources and effective and beneficial usage of the organization's properties. Meanwhile, the financial and accounting information accounts for a vast majority of the organization and the manager's informational needs so that, based on the studies, a big part of the managers' outputs are the financial ones, and most of the decisions made by managers are financial, business and economical. Obviously, the effectiveness of these decisions highly depends upon having exact and related information at the right time because, in the competitive strategies arena, among the organizations and companies only those would survive that are able to collect, analyze and report the reliable information in order to be used in decision-making and managing the organization.

Of the small and big economical units, industrial workshops employing 1-50 people account for about 99.6\%. This number of the industrial units making $50 \%$ of the total employment accounts for more than 2218 billion rials - 53.7\% of the total industrial products. The statistics just mentioned show the importance of small units in economical development. As accounting, informational systems are one the most vital managers' informational systems, compiling and implementing accounting systems is of high importance for these units (Statistics Center of Iran)

Unfortunately, the kind of information available for small units does not fulfill their specialized needs. Insufficient accounting information is the major reason for the failure of small business units every year, and part of it is due to accepted accounting principles and improper service for the clients provided by exterior accountants (Dethomas, Fredenberger, 1985).

In our country, the small units make a huge part of the economical institutions. According to the surveys, a considerable number of the small companies do not enjoy a proper information system, and the ineffective and inefficient accounting and financial unit among the various units has had numerous damages to the continuity of such economical units. Accurate and precise financial information are of the basic needs in the small business units (Dethomas and Fredenberger, 1985). Studies have shown that one of the main reasons for the failure of the small companies is poor financial reporting (Joshi \& Ramadhan, 2002). Decisions in such organizations are not made based on the financial information at the right time and, therefore, there is no descent attitude toward the position, role and output of accounting.

This research focuses on investigating the reasons and the factors of inefficiency in the accounting system and financial reporting referred to as the pathology of accounting and financial systems in small companies.

This study is to gather around reasons and evidences in order to answer this question properly:

What are the reasons for the inefficiency of accounting systems and financial reporting in small companies? 


\section{Theoretical Grounds}

\subsection{Accounting System and Financial Reporting}

a. efficient accounting system: a desirable (efficient) accounting system should have the following specifications and abilities:

- the correct identification and registration of economical events on the area of the economical activity of the institution

- the proper processing and analysis of the data

- providing results in forms of basic financial bills and internal and external financial reports

- fulfilling the informational expectations of the managers, investors, creditors, supervising and legal centers

- providing reliable information at the right time for decision-making

On the other hand, a proper and desirable accounting system should have these characteristics:

economical, practical, simple, flexible, providing reliable information at the right time, no mistakes and cheating, precise but useful.

b. inefficient accounting system: an accounting system is considered inefficient when it does not have the characteristics of a desirable accounting system and cannot perform the designated tasks in a desirable (efficient) accounting system.

\subsection{Small Companies}

Small institutions are the heart of the world's economy today. After the beginning of industrialization and development in countries, there was a competition in creating big industries and in mass and identical production, and reached the peak at the first three quarters of the $20^{\text {th }}$ century. But in the last quarter, the new concept of trading revolutionized the development and progress: "Small is beautiful". The last decade of the $20^{\text {th }}$ century saw the climax of technology and appearance of new methods in production and providing services. The newly started surge caused the small and medium technology institutions come into the focus of attention of the programmers in developed countries. The researchers and graduates of the universities got employed in small specialized companies that were the major window to technological development. What could not be achieved in big complex institutions, was made in laboratories with little facilities but with the high technology and knowledge of the entrepreneurs and experts in small institutions. A majority of the technological research projects are accompanied with a high risk. Failure of any kind could be the end of everything for the employees in such institutions (Kan’ani, Mousavi. Qasemi, Feisian, Asad Zamaneh, 2003).

Units and institutions are divided into small, medium and big based on the number of the work force and the amount of the capital. These institutions, because of their unique characteristics, have special functions such as:

- $\quad$ Originating jobs

- $\quad$ Distributing wealth in the society

- $\quad$ Developing the marginal areas

- $\quad$ Providing the needed productions for countries

- $\quad$ Training the work forces needed by institutions and big industries (Madadi, 2009)

\subsubsection{The Definition of Small Companies}

Small institutions are productive-business units, which are placed in lower categories than the big companies from the point of view of the size. The division of such institutions is usually based on four main guidelines:

- $\quad$ The number of the employees

- $\quad$ The pure total properties

- $\quad$ The sales level

- $\quad$ The investment level

The most important and usual guideline in determining the size of the small and medium institutions is the number of the employees. Although the number differs in countries, in most of them small and medium institutions are supposed to have one to two hundred and fifty employees (Madadi, 2009).

The small and medium institutions are similar to each other in spite of being in different countries. Anyway, no thorough definition can be given for them. Every country has provided a definition according to its own and special condition. Most of the definitions are based on quantitative criteria like the number of the employees and the annual financial circulation. For example, in the U.S. the institutions having less than 500 employees are considered as small, while in Germany the institutions having less than 10 are small, and 10 to 499 are medium. In a study done by International Industrial Development Center the small organizations are the one having less than 100 employees. By some 
organizations like the United Nations Industrial Development Organization the companies that employ 10 to 100 people and the value of the machinery is less than 7.5 million rials are considered as small (Salavati Sarcheshmeh, Maddah, Yazdani Rad, no date).

In the definition provided by the Organization of the Small Industries and Industrial Towns dependent on the Ministry of the Industries and Mines, the small productive units are those that:

a. Their capital is up to 7500 thousand rial in every productive unit

b. There are a maximum of 50 employees

c. Do not have any artistic attitude

d. Are mechanized

e. The investors are all Iranians

There is not just one definition for small institutions in Iran and every organization provides a definition of its own. According to the definition of the Ministry of the Industries and Mines, the small institutions are industrial and service units having less than 50 employees. The Statistics Center of Iran has divided businesses into four categories: 1-9, 10-49, 50-99 and more than 100 employees. Although this definition seems to have some things in common with the one provided by the EU for the small and medium institutions, The Statistics Center of Iran regards only the first group as small institutions and the others are considered as big industrial factories. The Central Bank of Iran names the institutions having less than 100 employees the small and medium institutions (Sharafi Nezhad, 2007). In this research, the definition of the Ministry of the Industries and Mines is taken.

\subsubsection{The Characteristics of the Small Business Units}

Small business units usually have some or all of the following characteristics:

- The operative ownership or control is restricted to one person or a few people and, so, the investor is the dominant.

- $\quad$ The accounting knowledge of the managing personnel or employees is limited

- $\quad$ Employing experienced and trained work forces in accounting is not possible or the manager is not interested

- $\quad$ There is a high possibility that interior controls get ignored by the manager

- Weakness in interior control

- $\quad$ The policy-making division (the directorate) of the business unit is inactive, and the tasks and the decisions of this division are operated in executive managers’ level (Jamaranian, 2002).

\subsubsection{The Problems of the Accounting Systems in Small Companies}

The failure of the small companies has some reasons as follows:

a. Ineffective or Inefficient Managing

One of the reasons of the failure in small companies is ineffective (inefficient) managing. In fact, the especially vulnerable units get in critical situation because of the lack of managing skills. Unfortunately, as the need for an effective (efficient) managing does not decrease with the decline in the size of the company, the managing problems and issues are more serious and critical in small companies. Some of the problems may be the following:

- Unclear understanding of the financial effects of the business operations, and inability in using operative information in the financial decision-making process

- $\quad$ Lack of knowledge in accounting and financial subjects by the founders

- Inability of the founders in employing proper and competent personnel: although having similar needs for financial information and interior financial controls exactly as big business units do, small business units do not even employ a part-time accountant.

- Another reason causing financial management problems in small companies is related to the information acquired by the managers (when the duty of accounting and keeping the financial records is left for an exterior accountant, the provided information in shape of traditional financial forms may be of little importance to the manager). Without having useful financial information, even demanding the preliminary financial management techniques is impossible and leads in misery. Therefore, informational systems and keeping financial records are necessary for small companies (DeThomas, Fredenberger, 1985).

b. Lack of Effective Interior Controls

Interior control without proper and sufficient accounting system is impossible (Nabavi, 1998). In most cases, the reason of the failure in these companies is the lack of effective interior controls. Some of the factors making problems are: 
- $\quad$ Owners/Managers that are not interested in interior control systems

- $\quad$ Lack of knowledge about such controls by managers/owners

- $\quad$ Very easy access to properties and accounting documents of the company

- $\quad$ Lack of the decision-making process based on information received from the accounting system (Leitch, Dillon, Mckinley 1981)

c. Other Weak Points in the Reporting System

Other possible weak points in the accounting system and financial reporting of some small units are:

1. being time-consuming,

2. being complicated,

3. imposing high expenses,

4. not being related,

5. not accepting accounting of the small units by freelance accountants: the accountant may come to this conclusion that because of the weaknesses due to the characteristics of the economical unit (like lack of accounting documents) gathering enough evidence in order to express any ideas about the financial forms is not possible. In such a situation, the accountant may decide either to refrain from accepting the job or to quit or to avoid expressing ideas.

\section{The Importance of the Subject and the Necessity to do the Research}

One of the fundamental problems in managing and supervising economical units is the inefficiency of the informational systems. Most of the informational systems are designed weakly and lack proper forms, trends and records. These weakly-designed systems bring about a decrease in the efficiency of the accountants and bookkeepers. Additionally, due to being designed unskillfully, there is too weak or no internal control in these systems (Esmaeilli, 1999).

If we keep it in mind that how important the small units are in developing and extending industry in the society, the problems of the accounting and financial systems in these units will show themselves better. These industries play a vital role from the point of view of both resolving unemployment, creating professional opportunities needed in the society, training industries managers, making industrial capital, the kind of their products in fulfilling basic and primary needs of the people, and the flexibility changing production line and economical maneuvers in the society. The role of small industries is known as important in economical-social development of the third-world countries because a group of theoreticians in the development of the third-world countries believe it is impossible or very difficult without creating or developing small industries. Therefore, it is important to pay serious attention to the problems of these industries, especially the financial, accounting and tax ones, in order to prevent more depression and suspension. The number of these problems would surely decrease by creating an efficient and desirable accounting system (Imani Rad, 1989).

Regarding the results obtained in the studies and surveys already done, a vast majority of the small economical units suffers from the lack of efficient accounting systems, and the existing accounting systems do not provide the necessary information for managers and other users in making economical decisions. So, surveying the reasons and the factors of the weakness in the accounting systems and financial reporting in small economical units is the main focus of this study.

\section{Reviewing the Literature}

None of the studies previously done on the subject of this study has focused on the pathology of the accounting system and financial reporting but the important examples related to the subject are:

Olivera, Martin, (2004) state the role of the problems of accounting in the failure of the small units. Of the mentioned cases, "incompetent and careless accountants" is the most important effective problem in the failure of the small units. In fact, incompetent and careless accountants are the most problematic factors in the failure of the small units. Incompetent or unskilled accountants are those who having left a bad impression of themselves for the owners of the small units. They are not trained for accounting and managing but have a claim on that. Careless accountants are the ones who may do their job either properly or not.

Paisey (2009) studied the role of the training in developing accounting students' skills. By comparing the viewpoints of the students attending the training course with those of the students having not attended, he stated that the training course is a useful means in creating transferable skills in students. Therefore, including training courses in the university accounting agenda can be useful.

Iraj Nourvash and Bita Mashayekhi in the journal of The Surveys in Accounting in 2005 in the article "The needs and Priorities of the Managing Accounting Training: Conceptional Gap between the University Graduates and the Incumbents of Accounting” asked whether there is a gap between managing accounting training and its presence in the 
profession or not, and in order to study this subject, the conception of the university graduates and the incumbents in the profession about what subjects are important in the managing accounting was studied.

Mojtahedzadeh (2001) by studying the viewpoints of the incumbents in accounting about the contents of the accounting agenda in B.A. in Iran universities states that:

1. we should include the training courses in the specialty courses, and

2. teaching computer usage should be of the specialty courses.

Mojtahedzadeh, Alavi Tabari, and Moradipour (2010) studied the importance and sufficiency of knowledge and required skills for the graduates of accounting, and also its importance from the viewpoint of the accounting professors, incumbents and students. The results showed that there is a meaningful relationship among the three groups of the respondents on the knowledge of analyzing financial forms, familiarity with the informational systems, knowledge of managing accounting, familiarity with the trade law, knowing the regulations of professional behavior, familiarity with the business techniques and the ability to manage organization's resources.

Having studied a collection of units of negotiable papers stock market in 1984, Byron and Friedlob in the journal of Management Accounting state that one of the reasons of the failure in small units the managers' and the owners' lack of knowledge about accounting and issues and, especially, managing accounting and interior controls.

DeThomas, Fredenberger (1985) in the article Accounting Necessities in Small Business Units mentioned that only 9\% of the managers-owners of the very small units are familiar with accounting, bookkeeping and financial issues, and $91 \%$ of the managers-owners have no familiarity with the accounting and financial issues. They also presented the characteristics of an informational system that likewise served for keeping financial records as follows:

- $\quad$ It must be meaningful for the users

- $\quad$ It must be adaptable (flexible) with special situations

- $\quad$ Its weak points and strong points must be able to be investigated

\section{The Hypotheses of the Study}

The following hypotheses are provided in order to answer the main question of the study:

1. Not employing the scientifically competent staff is the reason of the inefficiency of the accounting system and financial reporting in small companies.

2. Employing workforces with low job experience in accounting and financial affairs department is the reason of the inefficiency of the accounting system and financial reporting in these companies.

3. The irrelevancy between the professional requirements of the employees in the accounting and financial affairs department and the academic trainings in the relevant majors is the reason of the inefficiency of the accounting system and financial reporting in small companies.

4. Not establishing desirable systems designated to compensate the employees' services working in the accounting and financial affairs department is the reason of the inefficiency of the accounting system and financial reporting in small companies.

5. Unaware management of the function and role of the accounting and financial reporting in the process of managing and supervising the organization is the reason of the inefficiency of the accounting system and financial reporting in small companies.

6. Lack of legal and contract obligations in employing experts in financial and accounting professions is the reason of the inefficiency of the accounting system and financial reporting in small companies.

7. Lack of tax supervision and control on financial function in small companies is the reason of the inefficiency of the accounting system and financial reporting in these companies.

\section{The means of Gathering Information}

The information needed to do this study is gathered through observation, interview and questionnaires. In order to estimate the efficiency of the accounting system and financial reporting in small companies, a special form was prepared by the researcher and the advisor, and was filled out based on the researcher's observations and investigations on the quality of processing and registering the dealings, writing the registry notebooks, preparing financial forms and reports, preparing the reports for the legal and supervisory authorities, interior control system, etc. In addition to observations and interviews, in order to evaluate the knowledge of the manager of the business unit about financial issues, the presence of legal and contract obligations in employing expert staff in financial and accounting professions, and determining the gap between the professional requirements of the accounting department staff and academic trainings in 
relevant majors two separate questionnaires were prepared, one of which was filled out by the manager of the business unit and the other by the head of the accounting department in any company having studied in a major relevant to financial affairs.

\section{Statistical Society (community), Sampling and Estimating the Number of the Samples}

In this research, the statistical society includes all the small economical units in Sistan \& Baluchistan. The information was gathered in the simple random sampling method. On the $95 \%$ certainty level and with $10 \%$ allowed mistakes, the number of the samples, according to the following formula, is 96 and 100 companies were selected randomly out of the statistical society in order to gather information. The reliability of the questionnaire: the Cronbach alpha obtained from the SPSS software is 0.795 , so the questionnaire is of high reliability.

\section{The Variants}

In this study the expert competence of the staff in the financial department, experimental skill of the staff in the financial department, the gap between professional requirements of the staff in accounting and financial affairs department and the academic trainings in relevant majors, desirable systems for compensating the staff services in the accounting department, knowledge of the manager about the financial and accounting issues, legal and contract obligations in employing financial department staff, and tax supervisions and controls are considered as independent variants, and the efficiency of accounting system and financial reporting as dependant ones.

\section{Analyzing the Data and the Results of the Hypotheses Testing}

To analyze the statistical data, chi- square test and also the independent-samples $\mathrm{T}$ test of by means of the SPSS software are used.

\subsection{Testing the First Hypothesis}

To test the hypothesis "not employing the competent staff is the reason of the inefficiency of the accounting system and financial reporting in small companies", chi- square test was used and the results showed that not employing the scientifically competent staff is not the reason of the inefficiency of the accounting system and financial reporting in small companies (value $=0.229, \mathrm{df}=1$, sig $=0.632$ ).

\subsection{Testing the Second Hypothesis}

To test the hypothesis "Not employing the scientifically competent staff is the reason of the inefficiency of the accounting system and financial reporting in small companies chi- square test was used and the results showed not employing the scientifically competent staff is the reason of the inefficiency of the accounting system and financial reporting in small companies is the reason of the inefficiency of the accounting system and financial reporting in these companies (value $=8.691, \mathrm{df}=2$, sig= 0.013 ). The correlation quotient between the independent and dependant variant in this hypothesis is 0.367 .

\subsection{Testing the Third Hypothesis}

To test the hypothesis "the irrelevancy between the professional requirements of the employees in the accounting and financial affairs department and the academic trainings in the relevant majors is the reason of the inefficiency of the accounting system and financial reporting in small companies” in order or verify or reject it, the independent-samples $T$ test was used and the results showed that the irrelevancy between the professional requirements of the employees in the accounting and financial affairs department and the academic trainings in the relevant majors is the reason of the inefficiency of the accounting system and financial reporting in small companies.

Interpretation: levenes test compares the variance of the two groups; as the level of meaningfulness of this levenes test is more than $5 \%$, so one can suppose that the groups have the same variance. The level of meaningfulness of $t(0.05)$ shows that on the certainty level of $95 \%$ and with the level of freedom at 31 the difference between the averages is not accidental. Therefore, the zero theory is rejected and the hypothesis given in the study is accepted. Therefore, we can claim that the irrelevancy between the professional requirements of the employees in the accounting and financial affairs department and the academic trainings in the relevant majors is one of the reasons of the inefficiency of the accounting system and financial reporting in small companies.

Also for the five groups selected for the evaluation of the gap between professional requirements of the staff and academic trainings the $\mathrm{T}$ testing was carried out separately and the results showed that the factors of internship and probation while studying, ability to work with the computer and accounting softwares, and the ability to respond to the supervisory authorities have meaningful relationships with the efficiency of accounting system and financial reporting. 


\subsection{Testing the Fourth Hypothesis}

To test the hypothesis “Not establishing desirable systems designated to compensate the employees' services working in the accounting and financial affairs department is the reason of the inefficiency of the accounting system and financial reporting in small companies" chi- square test was used and the results showed that not establishing desirable systems designated to compensate the employees services working in the accounting and financial affairs department is the reason of the inefficiency of the accounting system and financial reporting in these companies (value $=12.009, \mathrm{df}=2$, sig=0.002). The correlation quotient between the independent and dependant variant in this hypothesis is 0.429.

\subsection{Testing the Fifth Hypothesis}

To test the hypothesis "Unaware management of the function and role of the accounting and financial reporting in the process of managing and supervising the organization is the reason of the inefficiency of the accounting system and financial reporting in small companies" chi- square test was used and the results showed that unaware management of the function and role of the accounting and financial reporting in the process of managing and supervising the is the reason of the inefficiency of the accounting system and financial reporting in these companies value $=27.042, \mathrm{df}=2$, sig=0.000). The correlation quotient between the independent and dependant variant in this hypothesis is 0.635 .

\subsection{Testing the Sixth Hypothesis}

To test the hypothesis "Lack of legal and contract obligations in employing experts in financial and accounting professions is the reason of the inefficiency of the accounting system and financial reporting in small companies”, chisquare test was used and the results showed that Lack of legal and contract obligations in employing experts in financial and accounting is not the reason of the inefficiency of the accounting system and financial reporting in small companies ? (value $=5.190, \mathrm{df}=2$, sig $=0.075$ ).

\subsection{Testing the Seventh Hypothesis}

To test the hypothesis "lack of tax supervision and control on financial function in small companies is the reason of the inefficiency of the accounting system and financial reporting in these companies”, chi- square test was used and the results showed that lack of tax supervision and control on financial function is not the reason of the inefficiency of the accounting system and financial reporting in small companies (value $=4.279, \mathrm{df}=2$, sig=0.118).

\section{Conclusion}

Small institutions are one of the influential factors in the growth and development of economies and the improvements in the people's lives and also the increase in employment or unemployment. Therefore much attention should be paid to creating and supporting such institutions in our country. However, unfortunately many of these units are facing numerous problems and barriers. A part of the problems is related to accounting and financial issues. Lack of an efficient accounting system and financial reporting has made it difficult for many of these units to continue existing. The accounting system is under the influence of many factors. The main purpose of this study is the pathology of the accounting systems and financial reporting in small companies, and investigating and studying the probable reasons and factors effective on the inefficiency and ineffectiveness of these systems in small companies. The findings showed that factors such as professional relevant experience of the staff in financial department, the gap between professional requirements of the staff and academic trainings, desirable systems for compensating the staff services in the accounting department, the knowledge of the manager of the business unit about financial and accounting issues have meaningful relationships with the efficiency of the accounting system and financial reporting, and parallel to the increase in any of them, the efficiency of the accounting system and financial reporting increases too. However, factors such as the competence of the staff in the accounting department, the presence of legal and contract obligations in employing staff in financial department and tax supervision and control did not have any meaningful relationships with the efficiency of the accounting system and financial reporting.

\section{Suggestions}

- Revision in the contents of educational agenda in accounting studying profiles and relevant majors

The testing of the third hypothesis indicates the presence of a gap between professional requirements of the staff and academic trainings that is regarded as a factor for the inefficiency of the accounting system and financial reporting in small companies. Therefore, it is suggested that in order to fill the gap between professional requirements of the staff and academic trainings the educational contents in the agenda in the relevant majors be revised. Giving a more effective role to the accounting courses of the companies and the information technology can considerably improve the specialized and skill arenas of the graduates in the relevant majors in playing the designated social roles.

- Requiring passing special probation courses for the students of accounting and relevant majors

Based on the results of testing the third hypothesis, it is suggested that in order to fill the gap between professional requirements of the staff and academic trainings, probation and skillfulness courses be included in academic agenda so that beside getting a proper understanding of the working environment and conditions of the accounting and financial activities, the students gain more knowledge about the professional expectations and requirements during the probation 
course. Probation courses are considered as a useful means of creating transferable skills in students and, therefore, it can be beneficial to include probation courses in academic agenda.

- Educating the managers and owners of the economical units and institutions in admitting students for probation courses

- When employing financial staff it is better to make sure of his/her ability in doing designated tasks by choosing the right way rather than paying attention only to the diploma he/she has.

- As the knowledge of managers-owners is so influential in the effectiveness and success of the accounting system and financial reporting, it is better for the managers and owners to try to enhance their knowledge about financial issues in different ways.

\section{Reference}

Amiri, H. (2000). Accounting system the proliferation centers and shrimp farms in Iran (M.Sc. Thesis, Tehran University, Tehran Central Branch).

Byron, E., \&Friedlob, G. (1984). Why small business fail. Management Accounting Journal, 16.

Canaani, M., Mousavi, S., Ghasemi, M., Faiziyan, A., \&Asdzmanh, K. (2003). Small and medium IT enterprises, definitions, strengths, weaknesses, opportunities and threats. Isfahan, paper presented at the Seventh Congress of the trilateral partnership of government, university and industry for national development, Isfahan.

DeThomas, A. R., \&Fredenberger, W. B. (1985). Accounting needs of very small business. The CPA Journal; 55, 000010, ABI/ inform global, pg 14.

Eimani rad, M.(1989). Small industries and accounting problems. Accountant Journal 3(7).

Information Center statistics ( 2009). The standard statistical definitions and concepts. Available: http://sci.org.ir

Ismaili, A. (1999). Study Weaknesses of financial systems to the building companies and Sales are the building blocks and provide an example of efficient financial systems(M.Sc. Thesis, Tehran University, Tehran Central Branch).

Jamaraniyan, R. (2002). Survey auditing problems of small business (the dissertation of M.Sc. in Tehran university)

Joshi, P., \& Ramadhan, S. (2002). The adoption of international accounting standards by small and closely held companies, evidence from Bahrain. The International Journal of Accounting, 37, pg429-440. http://dx.doi.org/10.1016/S0020-7063(02)00190-5

Leitch, R., Dillon, G., \& Mckinley, S. (1981). Internal control weaknesses in small businesses. Accountancy, 152, , 000006, ABI/ inform global, pg97.

Madadi Zadeh, H. (2009). Study Important criteria in the selection of accounting software for small and medium industries (Kerman) (Thesis, University of Sistan and Baluchistan).

Mojtahedzadeh, V. (2001). Accounting education in Iranian universities (undergraduate). Journal of Human Sciences, University of Al-Zahra, the eleventh $(37,38)$.

Mojtahedzadeh, V., Alavi, T., Seyyed H., \& Moradi par, F. (2010). Knowledge and skills required for undergraduate accounting students, views of university professors, and students working in the accounting profession. Accounting Knowledge, 1 (1), p. 73-87.

Nabavi, A. (1998). Auditing Principle. Eleven, Tehran: farvardin library.

Nuravesh, I., \& Mashayekhi, B. (2005). Educational needs and priorities of management accounting: conceptual gap between academics and practitioners in the accounting profession. Accounting and Auditing Review, 12 (41), p. 133-161.

Olivera, H. E., \& Martin, C. (2004). Accounting problems encountered in small business failures. Pg1-7.

Paisey, C. (2009). Developing skills via work placements in accounting :student and employer views. Accounting forum, in press, corrected proof. available online.

Salvati, S. B., Maddah, M., \& Yazdani-Rad, E. (no date).Policy and planning framework to support the creation and development of small and medium enterprises. Journal Parks and Incubators, 12: 39-49.

Sharafi, N. (2007). Review and prioritize the factors influencing the development of small and medium industries. Institute of Higher Education and Planning Management Research Related Organization's Planning Department.

Tady, M. (2002). Study Effects of inconsistencies in the accounting and budgetary system on the used management accounting report in the units covered by the Campaign Cooperative Foundation (Master's degree thesis, accounting, Imam Hossein University, Institute for the Humanities). 